\title{
Effect of renal denervation procedure on left ventricular hypertrophy of hypertensive rats and its mechanisms ${ }^{1}$
}

\author{
Efeito da denervação renal na hipertrofia do ventrículo \\ esquerdo de ratos hipertensos e seu mecanismo
}

\author{
Weihong Jiang, Lihua Tan", Yunzhong Guo ${ }^{\mathrm{III}}$, Xiaogang Li $^{\mathrm{IV}}$, Xiaohong Tang ${ }^{\mathrm{V}}$, Kan Yang ${ }^{\mathrm{II}}$ \\ IPhD, Associate Professor, Department of Cardiology, Third Xiangya Hospital, Central South University, Changsha, China. Main author. Design of \\ the study, manuscript writing. \\ IIFellow Master degree, Department of Cardiology, Third Xiangya Hospital, Central South University, Changsha, China. Acquisition of data, surgical \\ procedures. \\ IIIFellow Master degree, Department of Cardiology, Third Xiangya Hospital, Central South University, Changsha, China. Statistical analysis. \\ ${ }^{\mathrm{IV}}$ Fellow Master degree, Department of Cardiology, Third Xiangya Hospital, Central South University, Changsha, China. Critical revision. \\ v PhD, Associate Professor, Department of Cardiology, Third Xiangya Hospital, Central South University, Changsha, China. Critical revision. \\ ${ }^{v 1} \mathrm{PhD}$, Full Professor, Department of Cardiology, Third Xiangya Hospital, Central South University, Changsha, China. Design of the study, \\ manuscript writing, critical revision.
}

\begin{abstract}
PURPOSE: To investigate the effect of renal denervation (RDN) on the blood pressure, left ventricular hypertrophy and myocardial expression of TLR4/NF- $\kappa$ B in spontaneously hypertensive rats (SHR).

METHODS: A total of 36 SHR were randomly assigned into control group (D0), RDN group (D) and sham group (S). 12 WKY rats of same age served as controls (WKY group). Rats in the D0 and WKY groups were sacrificed, but rats in the D and S group were sacrificed at one week and six weeks after surgery. The heart was collected and the left ventricle weighted followed by calculation of left ventricular mass index (LVMI).

RESULTS: In the D0 group, the blood pressure, LVMI and protein expression of TLR4, NF- $\kappa$ B, TNF- $\alpha$ and IL-6 in the myocardium were markedly higher than that in the WKY group $(p<0.05)$. In the D1 and D2 group, the LVMI, NE and protein expression of TLR4, NF- $\kappa B$, TNF- $\alpha$ and IL- 6 in the myocardium were significantly reduced $(\mathrm{p}<0.05)$.

CONCLUSION: Renal denervation can significantly delay the progression of left ventricular hypertrophy in spontaneously hypertensive rats, which may be attributed to the not only the suppression of sympathetic activity and attenuation of pressure load but the improvement of myocardial immuno-inflammation.

Key words: Denervation. Kidney. Hypertrophy, Left Ventricular. Toll-Like Receptor 4. Ventricular Remodeling. Norepinephrine. Rats.
\end{abstract}

\section{RESUMO}

OBJETIVO: Investigar o efeito da denervação renal na pressão sanguínea, na hipertrofia do ventrículo esquerdo e a expressão miocárdica de TLR4/NF-kB em ratos espontaneamente hipertensos.

MÉTODOS: Trinta e seis SHR ratos foram aleatoriamente distribuídos em grupo controle, grupo denervação renal (D) e grupo sham(S). 12 WKY ratos de mesma idade serviram de controle. Os ratos controles foram sacrificados, mas os ratos com denervação renal e sham foram sacrificados uma semana e seis semanas após a cirurgia. O coração foi retirado e o ventrículo esquerdo pesado seguido pelo cálculo da massa ventricular (LVMI).

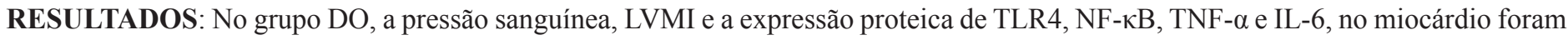
marcadamente maiores do que o grupo WKY $(\mathrm{p}<0,05)$. Nos grupos D1 e D2, o LVMI, NE e a expressão proteica de TLR4, NF-кB, TNF- $\alpha$ e IL-6 no miocárdio foi significantemente reduzido $(\mathrm{p}<0,05)$.

CONCLUSÃO: A denervação renal pode significantemente retardar a progressão da hipertrofia ventricular esquerda em ratos espontaneamente hipertensos, o que pode ser atribuído não apenas pela supressão da atividade simpática e atenuação da pressão, mas pela melhora na imunoinflamação miocárdica.

Descritores: Denervação. Rim. Hipertrofia Ventricular Esquerda. Receptor 4 Toll-Like. Remodelação Ventricular. Norepinefrina. Ratos. 


\section{Introduction}

Left ventricular hypertrophy ( $\mathrm{LVH})$ is one of common consequence of hypertension and studies have demonstrated that hyperactivity of sympathetic nervous system and immune/ inflammatory response play important role in the occurrence and development of $\mathrm{LVH}^{1,2}$. $\mathrm{LVH}$ has been found to be an independent risk factor of cardiovascular and cerebrovascular events ${ }^{3}$. To improve the prognosis of hypertension requires the reversion of LVH. Animal experiments showed inhibition of sympathetic nerves could confer protective effect on the damage to organs due to chronic excessive activation of sympathetic nerves ${ }^{4,5}$. Krum et $a l .{ }^{6}$ performed percutaneous renal artery ablation in the treatment of refractory hypertension. Their results showed the reduction of blood pressure was usually accompanied by the decrease in left ventricle mass. This suggests renal denervation can delay or even reverse the hypertension induced target organ damage, but the specific mechanism is still poorly understood. In the present study, renal denervation $(\mathrm{RDN})$ was done in spontaneously hypertensive rats (SHR) and the blood pressure, left ventricular mass index (LVMI) and expression of TLR4, NF- $\mathrm{B}, \mathrm{TNF}-\alpha$ and IL-6 in the myocardium were determined before and after RDN and the potential mechanism underlying the protective effect of RDN on LVH was explored.

\section{Methods}

The use of laboratory animals followed the Council for International Organization of Medical Sciences (CIOMS) ethical code for animal experimentation and was approved by the Ethics Committee of Central South University.

SHRs $(n=36)$ and age matched WKY rats $(n=12)$ weighing 240 280g were purchased from the Beijing Vitalriver Co., Ltd. Animals were housed until they were aged 12 weeks. Rabbit anti-rat TLR4 monoclonal antibody, rabbit anti-rat NF$\kappa \mathrm{B}$ P65 monoclonal antibody (SantaCruz), rabbit anti-rat TNF- $\alpha$ polyclonal antibody, rabbit anti-rat IL-6 polyclonal antibody (Wuhan Boster Biotech Co., Ltd) and goat anti-rabbit IgG (Proteintech, USA) were used in the present study.

\section{Grouping}

SHRs ( $\mathrm{n}=36$ ) were randomly assigned into control group (D0 group), surgery group (D group) and sham group (S group). The age matched WKY rats $(n=12)$ served as controls (WKY group). Animals were housed until they were aged 12 weeks. Rats in the D0 group and WKY group were sacrificed. At one week after surgery, rats in the D1 group and S1 group were killed; at six weeks after surgery, rats in the D2 group and S2 group were killed. Six rats were sacrificed at each time point in each group and the heart and kidney was collected for use.

\section{$R D N$ procedure}

Rats were anesthetized intraperitoneally with chloral hydrate at $25 \mathrm{mg} / \mathrm{kg}$. After sterilization, a midline incision was made in the abdomen followed by exposure of subcutaneous tissues and the kidneys. The ureters and the arteries, veins and nerves in the sheath were observed. After stripping the arterial/venous sheath, the renal nerve was exposed followed by denervation under a microscope $(25 \mathrm{x})$. Then, the $10 \%$ phenol in $95 \%$ ethanol was used to treat the tissues surrounding the veins. In the sham group, laparotomy was performed and sympathetic nerve was exposed and treated with normal saline. Then, the wound was closed and rats were allowed to wake spontaneously. Within three days after surgery, intraperitoneal injection of $16 \mathrm{U}$ of penicillin was performed for prevention of infection.

\section{Measurement of blood pressure}

Non-invasive blood pressure measuring instrument was used to measure the blood pressure at the tail artery. At room temperature, the rest rats were fixed on a table and the balloon of measuring instrument was inserted into the proximal end of tail artery and the pulse transducer was placed in the balloon. Then, the temperature was increased to 39 aiming to completely dilate the tail artery. The other end of the instrument was connected to a computer via a 4-Channel Dynamic Signal Acquisition system. When the signals became stable, the balloon was inflated until the pulse signal became a straight line followed by deflation. When the pulse signals formed regular waves, the blood pressure was calculated spontaneously. Blood pressure was measured once every 3 min for three times and the mean was calculated.

\section{Measurement of LVMI}

After killing the rats, the heart was collected and the major blood vessels, atriums and right ventricle were separated along the atrioventricular junction. The tissues were washed completely with pre-cooled PBS and the residual water was removed. Then, the left ventricle (including ventricular septum) was weighed and the ratio of left ventricle to body weight was calculated as LVMI. 


\section{Measurement of norepinephrine in kidney}

The kidney was collected from each rat and highperformance liquid chromatography coupled with electrochemical detection (HPLC - ECD) was performed to measure the norepinephrine (NE) in the kidney. In brief, the kidney was homogenized in $5 \%$ perchloric acid followed by centrifugation at $15000 \mathrm{r} / \mathrm{min}$ at $4^{\circ} \mathrm{C}$ for $10 \mathrm{~min}$. The supernatant $(20 \mu \mathrm{l})$ was collected for detection. External standard method was employed for quantification, and the NE content was calculated according to the regression equation.

Detection of TLR4, TNF- $\alpha$ and IL-6 expression in myocardium by immunohistochemsitry

SABC was performed for immunohistochemsitry. In brief, the myocardium was processed and embedded in paraffin followed by sectioning $(5 \mu \mathrm{m}$ in thickness). The sections underwent deparaffinization and then treated with $3 \% \mathrm{H}_{2} \mathrm{O}_{2}$ to block the endogenous peroxidase. The sections subsequently received antigen retrieval in $0.01 \mathrm{mmol} / \mathrm{L}$ citrate buffer $(\mathrm{pH}=6.0)$ at 80 (95 for TNF- $\alpha$ and IL-6) for $20 \mathrm{~min}$. After washing in PBS, these sections were treated with animal serum at room temperature for $2 \mathrm{~h}$ for blocking non-specific binding and then with primary antibody (TLR4, TNF- $\alpha$ or IL-6; 1:100) at room temperature overnight. Following washing in PBS, sections were treated with secondary antibody for $2 \mathrm{~h}$ in a humidified environment and then with HRP conjugated streptavidin for $2 \mathrm{~h}$. Visualization was done with DAB and reaction was stopped by addition of PBS. Following dehydration and transparentization, mounting was performed.

Detection of protein expression of TLR4, NF- $\kappa B, T N F-\alpha$ and IL-6 in myocardium by western blot assay

For the detection of TLR4, TNF- $\alpha$ and IL-6, the rat myocardium was homogenized and lysed in RIPA lysis buffer followed by extraction of total protein. For the detection of NF$\kappa \mathrm{B}$, the nuclear protein was extracted from the myocardial cells with Nuclear Extraction Kit. Proteins were subjected to SDSPAGE for separation and then transferred onto PVDF membranes which were then blocked in 5\% non-fat milk in TBST for $1 \mathrm{~h}$. Then, the membranes were treated with primary antibody $(1: 1000)$ at 4 overnight. $\beta$-actin served as an internal reference. Then, the membranes were washed in TBS and treated with HRP conjugated secondary antibody (1:3000; Proteintech) for 45-60 min. After washing in TBS, visualization was done with ECL reagents. The bands were scanned and analyzed with Quantity One software.
The expression of target genes was normalized to that of $\beta$-actin as the relative expression.

\section{Statistical analysis}

SPSS version 16.0 was employed for statistical analysis. Data were expressed as mean \pm standard deviation $(\bar{x} \pm s)$. Means among different groups were compared with LSD test, and Twovariable linear regression analysis was employed for correlation analysis. A value of $\mathrm{p}<0.05$ was considered statistically significant.

\section{Results}

\section{General data}

There were no significant differences in the heart rate and body weight among WKY group, D0 group, surgery group and sham group $(\mathrm{p}>0.05)$.

\section{Changes in SBP, DBP and LVMI in different groups}

In the D0 group, the SBP, DBP and LVMI were markedly higher than those in the WKY group $(\mathrm{p}<0.05)$. In the D1 group, the SBP, DBP and LVMI were significantly lower than those in the D0 group and S1 group $(\mathrm{p}<0.05)$. In the D2 group, the SBP and DBP increased as compared to the D1 group but was comparable to that in the D0 group and S2 group ( $\mathrm{p}>0.05)$. The LVMI in the D2 group was increased when compared with the D0 group but still markedly lower than that in the S2 group $(\mathrm{p}<0.05)$ (Table 1).

TABLE 1 - SBP, DBP and LVMI in different groups ( $\bar{x} \pm s)$.

\begin{tabular}{|c|c|c|c|c|c|c|}
\hline \multirow{2}{*}{ Group } & \multirow{2}{*}{$\begin{array}{c}\text { WKY group } \\
(\mathrm{n}=12)\end{array}$} & \multirow{2}{*}{$\begin{array}{l}\text { D0 group } \\
(\mathrm{n}=12)\end{array}$} & \multicolumn{2}{|c|}{ D group } & \multicolumn{2}{|c|}{$\mathrm{S}$ group } \\
\hline & & & DI $(\mathrm{n}=6)$ & $\mathrm{D} 2(\mathrm{n}=6)$ & $\mathrm{S} 1(\mathrm{n}=6)$ & $\mathrm{S} 2(\mathrm{n}=6)$ \\
\hline $\mathrm{SBP}(\mathrm{mmHg})$ & $140.0 \pm 10.86$ & $201.67 \pm 11.09$ (1) & $157.30 \pm 9.35(2)(3)$ & $208.83 \pm 10.23$ & $197.30 \pm 11.5$ & $197.50 \pm 12.13$ \\
\hline DBP (mmHg) & $78.50 \pm 7.32$ & $144.50 \pm 10.48(1)$ & $112.50 \pm 6.25(2)(3)$ & $150.33 \pm 7.74$ & $146.80 \pm 7.6$ & $151.50 \pm 8.22$ \\
\hline LVMI (mg $/ \mathrm{g})$ & $1.93 \pm 0.05$ & $2.44 \pm 0.05$ (1) & $2.32 \pm 0.04(2)(3)$ & $2.46 \pm 0.07(4)$ & $2.57 \pm 0.09$ & $2.81 \pm 0.05$ \\
\hline $\mathrm{NE}$ & $0.13733 \pm 0.039$ & $0.25109 \pm 0.088$ (1) & $0.0397 \pm 0.0325(2)(3)$ & $0.2285 \pm 0.1082$ (4) & $0.3162 \pm 0.0735$ & $0.48756 \pm 0.1856$ \\
\hline
\end{tabular}

Note: $1 \mathrm{p}<0.05$ vs WKY group; $2 \mathrm{p}<0.05$ vs D0 group $3 \mathrm{p}<0.05$ vs $\mathrm{S} 1$ group; $4 \mathrm{p}<0.05$ vs $\mathrm{S} 2$ group 
Immunohistochemsitry for TLR4, TNF- $\alpha$ and IL-6

Results showed the expression of TLR4, TNF- $\alpha$ and IL-6 in the myocardium increased in SHR over age. In the SHR undergoing RDN, the expression of TLR4, TNF- $\alpha$ and IL- 6 was lower than that in the rats of sham group (Figures 1 to 3 ).
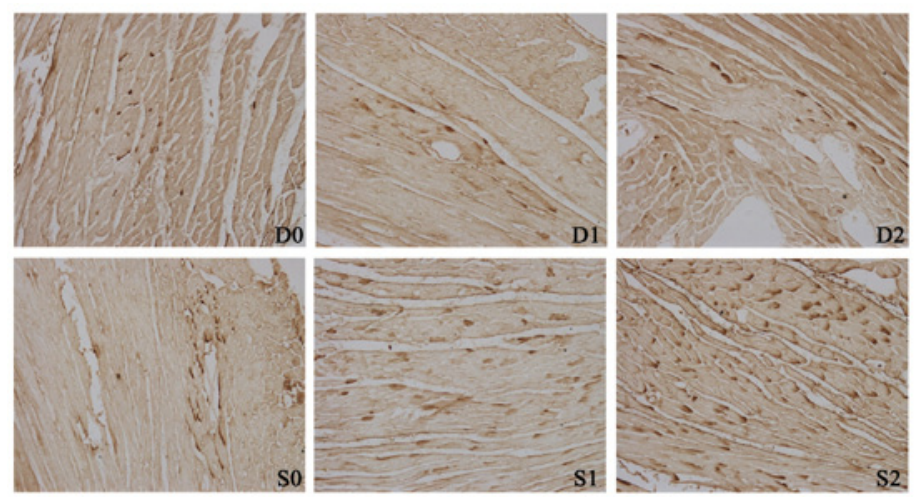

FIGURE 1 - TLR4 expression in the myocardium (200x). TLR4 expression in the myocardium increased in SHR over age $(\mathrm{p}<0.05$ : S0 vs $\mathrm{S} 1 ; \mathrm{S} 0$ vs S2). In the SHR undergoing RDN, the TLR4 expression was markedly lower than that in the rats of sham group ( $<<0.05$ : D1 vs S1; D2 vs S2).
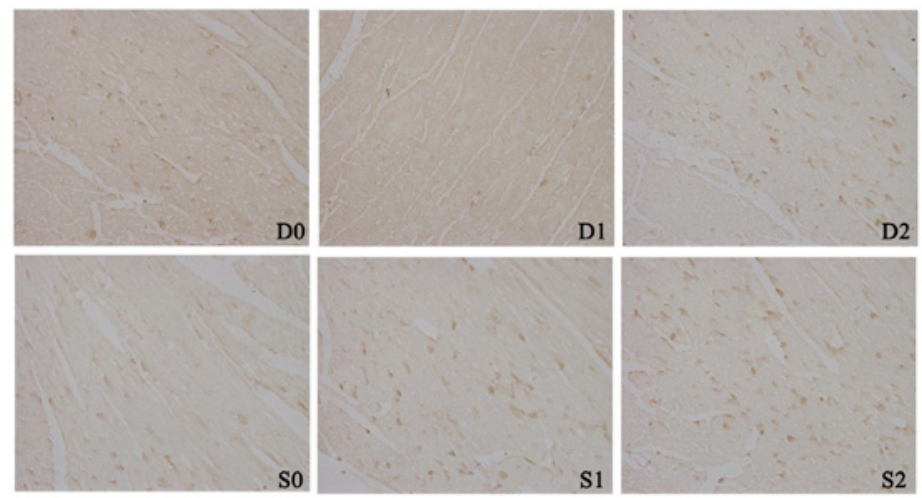

FIGURE 2 - IL-6 expression in the myocardium (200x). IL-6 expression in the myocardium increased in SHR over age $(\mathrm{p}<0.05$ : S0 vs S1; S0 vs $\mathrm{S} 2$ ). In the SHR undergoing RDN, the IL-6 expression was significantly lower than that in the rats of sham group ( $\mathrm{p}<0.05$ : D1 vs S1; D2 vs S2).
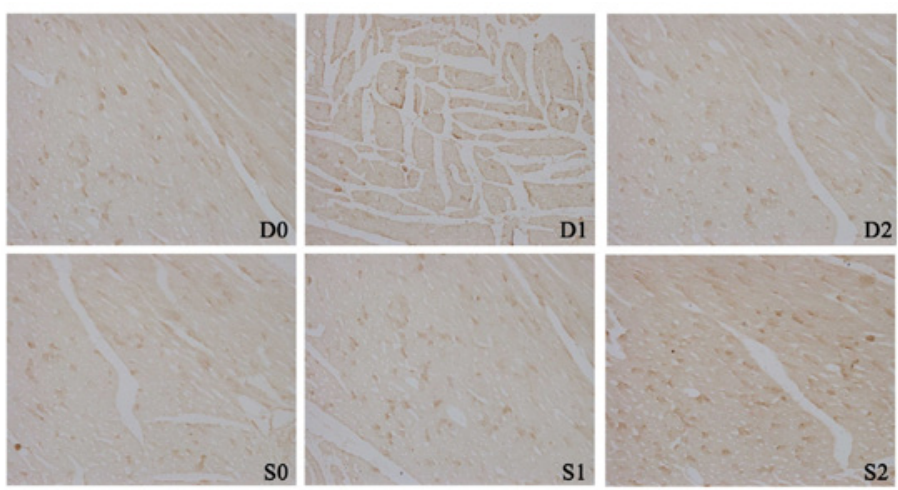

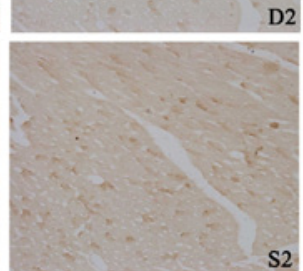

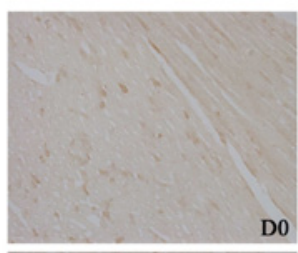

FIGURE 3 - TNF- $\alpha$ expression in the myocardium (200x). TNF- $\alpha$ expression in the myocardium increased in SHR over age ( $<<0.05$ : S0 vs $\mathrm{S} 1 ; \mathrm{S} 0$ vs S2). In the SHR undergoing RDN, the TNF- $\alpha$ expression was dramatically lower than that in the rats of sham group ( $\mathrm{p}<0.05$ : D1 vs $\mathrm{S} 1$; D2 vs S2).
Western blot assay for TLR4, NF- $\kappa B, T N F-\alpha$ and IL-6

In the D0 group, the expression of TLR4, NF- $\kappa \mathrm{B}, \mathrm{TNF}-\alpha$ and IL-6 was markedly higher than that in the WKY group $(p<0.05)$. At one week after surgery, the expression of TLR4, NF$\kappa \mathrm{B}, \mathrm{TNF}-\alpha$ and IL- 6 in the D1 group were dramatically reduced when compared with D0 group and S1 group $(p<0.05)$. At six weeks after surgery, the expression of TLR $4, N F-\kappa B, T N F-\alpha$ and IL-6 in the D2 group was only slightly higher than that in the D0 group ( $p>0.05)$ but markedly lower than that in the S2 group $(\mathrm{p}<0.05)$ (Table 2, Figure 4).

TABLE 2 - Semi-quantitative detection of protein expression of TLR $4, N F-\kappa B, T N F-\alpha$ and IL-6 in the myocardium of rats in different groups $(\bar{x} \pm s)$.

\begin{tabular}{lccccc}
\hline Group & $\mathrm{n}$ & TLR4 & NF-KB & TNF- $\alpha$ & \multicolumn{1}{c}{ IL-6 } \\
\hline WKY & 12 & $0.126 \pm 0.004$ & $0.195 \pm 0.005$ & $0.146 \pm 0.004$ & $0.207 \pm 0.006$ \\
D0 & 12 & $0.298 \pm 0.004(1)$ & $0.249 \pm 0.006(1)$ & $0.323 \pm 0.004(1)$ & $0.283 \pm 0.005(1)$ \\
D1 & 6 & $0.198 \pm 0.006(2)(3)$ & $0.208 \pm 0.006(2)$ & $0.27 \pm 0.009(2)(3)$ & $0.218 \pm 0.004(2(3)$ \\
S1 & 6 & $0.317 \pm 0.008$ & $0.332 \pm 0.007$ & $0.375 \pm 0.004$ & $0.376 \pm 0.009$ \\
D2 & 6 & $0.301 \pm 0.009(4)$ & $0.251 \pm 0.004(4)$ & $0.324 \pm 0.005(4)$ & $0.285 \pm 0.009(4)$ \\
S2 & 6 & $0.567 \pm 0.006$ & $0.476 \pm 0.009$ & $0.535 \pm 0.006$ & $0.549 \pm 0.007$ \\
\hline
\end{tabular}

Note: $1 \mathrm{p}<0.05$ vs WKY group; $2 \mathrm{p}<0.05$ vs D0 group $3 \mathrm{p}<0.05$ vs $\mathrm{S} 1$ group; $4 \mathrm{p}<0.05$ vs $\mathrm{S} 2$ group5

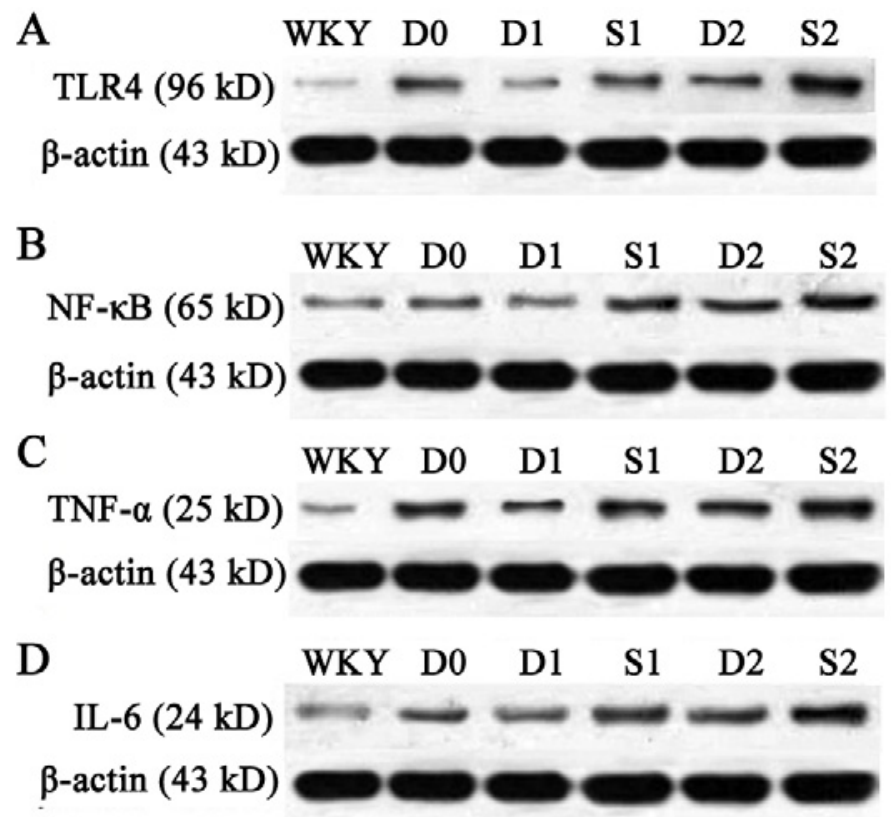

FIGURE 4 - Protein expressions in the myocardium of rats in different groups. A, TLR4; B, NF- $\kappa$ B; C, TNF- $\alpha$; D, IL-6. 


\section{Discussion}

Chronic activation of renal sympathetic nervous system play important roles in the occurrence and development of hypertension and hypertension induced target organ damage. Animal experiments have demonstrated that RDN can delay the occurrence of hypertension or reduce the blood pressure ${ }^{7}$. In recent years, treatment of hypertension and diseases due to chronic hyperactivity sympathetic nervous system (such as heat failure, hypertension accompanied by impaired glucose tolerance and chronic renal dysfunction) with RDN has been a hot topic in the research ${ }^{8-10}$. Krum et al. ${ }^{6}$ found that RDN not only reduced the blood pressure, but conferred protective effect on hypertension induced LVH, but the mechanism was still unclear. In the present study, RDN was performed in SHRs and results showed the blood pressure and LVMI reduced significantly at one week after surgery, At one week after surgery, the NE in the kidney was markedly reduced as compared to the control group, suggesting complete dennervation, which was consistent with findings of Krum et al. ${ }^{6}$ However, at six weeks after surgery, the blood pressure increased again and was comparable to that in the D0 group and sham group although the blood pressure was still slightly lower than that in the D0 group and sham group. The NE increased to a certain extent and returned to nearly normal. This suggests the disconnected nerves regenerate. However, the LVMI in the rats undergoing RDN was still significantly lower than that in the sham group. This indicates that other mechanism may attributed to the protective effect of RDN on LVH

Numerous studies have found that hypertension induced LVH is a chronic inflammation ${ }^{11,12}$. Immune/inflammation plays an important role in the occurrence and development of LVH as a result of hypertension. To date, TLR4 and TLR4 mediated $\mathrm{NF}-\kappa \mathrm{B}$ signaling pathway are closely related to the occurrence and development of hypertension induced LVH. TLR4 and related signals can activate primary immunity and inflammation involving in the formation and progression of $\mathrm{LVH}^{13-15}$. Our results showed, when compared with WKY rats aged 12 weeks, age matched SHRs developed increased blood pressure and evident LVH, and the LVH progressed in SHRs with the increase in course of hypertension, accompanied by increased expression of immune/inflammatory cytokines including TLR $4, \mathrm{NF}-\kappa \mathrm{B}, \mathrm{TNF}-\alpha$ and IL-6. This further demonstrates that immune-inflammation definitely involves in the development of LVH in SHRs. In our previous study, the blood pressure, NE in the kidney and expression of inflammatory cytokines in the myocardium in the blank control group were comparable to those in the sham group, which excluded the influence of surgery on these parameters. Previous studies showed the interaction between the nervous system and the immune/inflammatory response ${ }^{16,17}$. Theoretically, inhibition of sympathetic nervous system may compromise the immune/inflammatory response, which may further improve the LVH. In the present study, our findings demonstrated the postoperative changes in LVMI, and the changes in the expression of inflammatory cytokines (TLR4, NF- $\kappa$ B, TNF- $\alpha$ and IL-6) in the myocardium were consistent to those in LVMI. This suggested that the improvement of left ventricular hypertrophy after dennervation was related to the alteration of myocardial immuno-inflammation. In the present study, our findings revealed the changes in the expression of inflammatory cytokines were consistent with those in LVMI in rats undergoing RDN, and correlation analysis showed LVMI was related to the expression of TLR $4, N F-\kappa B, T N F-\alpha$ and IL-6 in the myocardium. These demonstrate that post-operative improvement of LVH is closely related to the alteration of immune/ inflammatory reaction in local myocardium. On the basis of findings in the present study and previous studies, we postulate that RDN improving LVH in SHR is attributed to both the suppression of sympathetic activity, alleviation of pressure load and inhibition of immune/inflammatory reaction in local myocardium.

Taken together, both sympathetic nervous system and immune/inflammatory reaction involve in the occurrence and development of hypertension induced LVH and there is interaction between them. Both sympathetic nervous system and immune/ inflammatory reaction promote the progression of LVH. RDN confers protective effect on hypertension and hypertension induced target organ damage via inhibiting both sympathetic nervous system and immune/inflammatory reaction, which is crucial for the improvement of prognosis of hypertension. However, the regeneration of disconnected nerves and/or the feedback regulation of systemic sympathetic nervous system are possibly to compromise the long term efficacy of RDN, and more follow up studies are required to confirm the long term efficacy of RDN.

\section{Conclusion}

Renal denervation can significantly delay the progression of left ventricular hypertrophy in spontaneously hypertensive rats, which may be attributed to the not only the suppression of sympathetic activity and attenuation of pressure load but the improvement of myocardial immuno-inflammation. 


\section{References}

1. Dorn GW 2nd. The fuzzy logic of physiological cardiac hypertrophy. Hypertension. 2007;49:962-70.

2. Salles GF, Fiszman R, Cardoso CR, Muxfeldt ES. Relation of left ventricular hypertrophy with systemic inflammation and endothelial damage in resistant hypertension. Hypertension. 2007;50:723-8.

3. Bombelli M, Facchetti R, Carugo S, Madotto F, Arenare F, QuartiTrevano F, Capra A, Giannattasio C, Dell'Oro R, Grassi G, Sega R, Mancia G. Left ventricular hypertrophy increases cardiovascular risk independently of in-office and out-of office blood pressure values. J Hypertens. 2009;27:2458-64.

4. DiBona GF. Neural control of the kidney: past, present, and future. Hypertension. 2003;41:621-4.

5. Dibona GF. Physiology in perspective: The Wisdom of the body. Neural control of the kidney. Am J Physiol Regul Integr Comp Physiol. 2005;289:R633-41.

6. Krum H, Schlaich M, Whitbourn R, Sobotka PA, Sadowski J, Bartus K, Kapelak B, Walton A, Sievert H, Thambar S, Abraham WT, Esler M. Catheter-based renal sympathetic denervation for resistant hypertension a multicentre safety and proof-of-principle cohort study. Lancet. 2009;373:1275-81.

7. Weinstock M, Gorodetsky E, Kalman R. Renal denervation prevents sodium retention and hypertension in salt-sensitive rabbits wit $h$ genetic baroreflex impairment. Clin Sci (Lond). 1996;90:287-93.

8. Kimura G, Fukuta H. Catheter-based renal sympathetic denervation for treatment of hypertension (J). Nippon Naika Gakkai Zasshi. 2011;100:441-5.

9. Mahfoud F, Schlaich M, Kindermann I, Ukena C, Cremers B, Brandt MC, Hoppe UC, Vonend O, Rump LC, Sobotka PA, Krum H, Esler M, Böhm M. Effect of renal sympathetic denervation on glucose metabolism in patients with resistant hypertension: a pilot study. Circulation. 2011;123:1940-6.

10. Prochnau D, Lauten A, Busch M, Kuehnert H, Figulla HR, Surber R. Catheter-based radiofrequency ablation therapy of the renal sympathetic-nerve system for drug resistant hypertension in a patient with end-stage renal disease. Int J Cardiol. 2011;5:234-9.

11. Kuwahara F, Kai H, Tokuda K, Takeya M, Takeshita A, Egashira $\mathrm{K}$, Imaizumi T. Hypertensive myocardial fibrosis and diastolic dysfunction. Another model of inflammation? Hypertension. 2004;43:739-45.

12. Tsioufis C, Stougiannos P, Kakkavas A, Toutouza M, Mariolis A, Vlasseros I, Stefanadis C, Kallikazaros I. Relation of left ventricular concentric remodeling to levels of C-reactive protein and serum amyloid A in patients with essential hypertension. Am J Cardiol. 2005;96:252-6.

13. Frantz S, Kobzik L, Kim YD, Fukazawa R, Medzhitov R, Lee RT, Kelly RA. Toll4 (TLR4) expression in cardiac myocytes in normal and failing myocardium. J Clin Invest. 1999;104:271-80.

14. Zhang D, Gaussin V, Taffet GE, Belaguli NS, Yamada M, Schwartz RJ, Michael LH, Overbeek PA, Schneider MD. TAK1 is activated in the myocardium after pressure overload and is sufficient to provoke heart failure in transgenic mice. Nat Med. 2000;6:556-63.

15. Purcell NH, Molkentin JD. Is nuclear factor- $\mathrm{KB}$ an attractive therapeutic target for treating cardiac hypertrophy. Circulation. 2003;108:638-40.

16. Chrousos GP. The stress response and immune function: clinical implications. Ann NY Acad Sci. 2000;917:38-47.

17. Levick SP, Murray DB, Janicki JS, Brower GL. Sympathetic nervous system modulation of inflammation and remodeling in the hypertensive heart. Hypertension. 2010;55:270-6.

\section{Correspondence:}

Prof. Kan Yang

Department of Cardiology

Third Xiangya Hospital, Central South University

Changsha, 410013, China

yang32432423@sohu.com

Received: June 12, 2012

Review: August 14, 2012

Accepted: September 13, 2012

Conflict of interest: none

Finance source: Project of Science and Technology Agency of Hunan Province (2011FJ4269)

${ }^{1}$ Research performed at Experimental Center, Third Xiangya Hospital, Central South University, Changsha, China. 